\title{
The Impact of the Depth of Embryo Replacement into the Uterine Cavity under Transabdominal Ultrasound Guidance on In Vitro Fertilization and Embryo Transfer Outcome
}

\author{
Mitko Ivanovski ${ }^{1^{*}}$, Slavjanka Popovska ${ }^{2}$ \\ ${ }^{1}$ Clinical Hospital Acibadem Sistina, Gynaecology and Obstetrics, Skupi 5A, Skopje 1000, Republic of Macedonia; ${ }^{2}$ PZU "S. \\ Popovska", Skopje 1000, Republic of Macedonia
}

\begin{abstract}
Citation: Ivanovski M, Popovska S. The Impac of the Depth of Embryo Replacement into the Uterine Cavity under Transabdominal Ultrasound Guidance on In Vitro Fertilization Ultrasound Guidance on In Vitro Fertilization and Embryo Transfer Outcome. OA Maced Med Sci. 2013 Dec 15; 1(1):38-44 http://dx.doi.org/10.3889/oamjms.2013.008 Key words: depth of embryo replacement; endometrium; ultrasound; in vitro fertilization; pregnancy rate.

"Correspondence: Mitko Ivanovski, MD Clinical Hospital Acibadem Sistina Gynaecology and Obstetrics, Skupi 5A, Skopje 1000, Republic of Macedonia. E-mail mitko_ivanovski@live.com

Received: 12-Sep-2013; Revised: 25-Sep2013; Accepted: 17-Oct-2013; Online first: 25-Oct-2013

Copyright: () 2013 Ivanovski M. This is an open-access article distributed under the terms of the Creative Commons Attribution License, which permits unrestricted use, distribution, and reproduction in any medium, provided the original author and source are credited.

Competing Interests: The authors have declared that no competing interests exist.
\end{abstract}

\begin{abstract}
Aim: The aim of the present study was to determine the importance of the depth of embryo replacement into the uterine cavity (upper or lower half endometrial cavity) on the implantation clinical pregnancy rates.

Material and Methods: In this prospective observational were included 160 patients underwent controlled ovarian hyperstimulation followed by IVF/ICSI and embryo transfer. On the day of embryo transfer under direct transabdominal ultrasound guidance, the transfer catheter was advanced to a defined distance from the uterine fundus, up to the point estimated for transfer: $10 \pm$ $2.5 \mathrm{~mm}$ (Group A) and $15 \pm 2.5 \mathrm{~mm}$ (Group B).
\end{abstract}

Results: In total, 160 patients, aged 24-42 years were included in the study. Overall clinical pregnancy rate were $41.2 \%$. Analysis of our results demonstrated that pregnancy rate is significantly influenced by transfer distance from the fundus where the pregnancy rate decreases from $48.7 \%$ in group $B$ to $34.5 \%$ in group $A(p<0.05)$. There was not significantly difference in abortion rate between the two groups.

Conclusion: In conclusion, our results suggest that depth of embryo replacement inside the uterine cavity may influence the pregnancy rates and should be considered as an important factor to improve the success of IVF cycles.

\section{Introduction}

The embryo transfer procedure is the last one of the in vitro fertilization process. No matter how good the IVF laboratory culture environment is, the physician can ruin everything with a carelessly performed embryo transfer. The entire IVF cycle depends on delicate placement of the embryos at the proper location on the endometrial cavity - with minimal trauma and manipulation. Improvements in in vitro fertilization (IVF) and embryo transfer (ET) have resulted from evaluating each step of the process, analyzing effects of different techniques, then assessing outcomes to select the best method, whether related to preparation of the patient, choice of stimulation protocol, culture technique, embryo selection, mechanics of transfer, or post transfer management. Despite numerous developments in assisted reproduction, the clinical pregnancy rate (CPR) in in vitro fertilization (IVF) and intracytoplasmic sperm injection (ICSI) remains low. It has been estimated that up to $85 \%$ of the embryos replaced into the uterine cavity fail to implant [1]. The main variables that affect nidation are related to uterine receptivity, embryo quality and the efficiency of embryo transfer. 
Embryo transfer is maybe the most important, final, critical step in assisted reproductive technology, with rigid catheters, contamination with blood, mucus or bacteria, increased contraction waves of the myometrium, and the level of difficulty in introducing the catheter inside the uterine cavity tending to reduce embryo implantation rates [2-10].

Embryo transfer may be performed in one of two ways: blindly by clinical touch, or with ultrasonographic guidance. The failure of most embryos to implant after transfer prompted interest in US-guided embryo transfer in an attempt to improve pregnancy rate (PR). The use of US for embryo transfer was first described by Strickler et al. in 1985 [11], who found US guidance easier and associated with less catheter distortion than embryo transfer without US guidance. Since then, several investigators have described an overall trend toward higher PRs with US [12-19].

Most IVF teams consider not touching the endometrium and the uterine fundus with replacement of the embryos in the lumen of the endometrial cavity the most important factors for successful embryo transfer [20, 21]. It has been traditionally accepted that the embryo should be placed $5-10 \mathrm{~mm}$ from the endometrial cavity fundus [22]. In addition, some authors have suggested that placing embryos rather lower in the uterine cavity may improve pregnancy rate [18, 23-28].

The aim of the present study was to determine the importance of the depth of embryo replacement into the uterine cavity (upper or lower half endometrial cavity) on the implantation and clinical pregnancy carried out under transabdominal ultrasound guidance.

\section{Materials end Methods}

Between April 2012 and September 2013, a total 160 patients at the IVF unit in Clinical Hospital Acibadem Sistina were found to be eligible for this prospective study. All couples previously had been evaluated by day 3 hormone levels, preovulatory US evaluation, hysterosalpingography, semen analysis, and hysteroscopy and laparoscopy, if indicated. The age range of the women was 22-42 years. The predominant diagnoses were male factor, tubal factor or unexplained infertility. The inclusion criteria were that the participant had a normal basal FSH level per our laboratory $(</=14 \mathrm{mIU} / \mathrm{mL})$, presence of both ovaries (ability to visualize both ovaries on transvaginal ultrasonography) and absence of ovarian abnormalities or ovarian cysts $>10 \mathrm{~mm}$. All patients were included in this study only once to avoid selection bias. Exclusion criteria were history of ovarian or uterine surgery, distortions of the uterine cavity or apparent endometrial pathologies (submucous myoma, synechia, polyps, etc.). Women who had three or more failed attempts at IVF and embryo transfer or who received frozen-thawed embryos were not included.

Women undergoing ovulation induction were routinely down-regulated with triptorelin acetate (Decapeptyl, $0.1 \mathrm{mg}$; ER-KIM, Ilac San.; $0.1 \mathrm{mg} / \mathrm{d}$ ) or busereline acetate SC (Suprefact $7 \mathrm{ml}$; Aventis Pharma Deutchland $\mathrm{GmbH} ; 0.5 \mathrm{mg} / \mathrm{d}$ ) starting from the 21 st day of the preceding cycle in long down-regulation protocol and from the 2nd day of the cycle in the short down-regulation protocol. The analogue was continued until the day of HCG. After the downregulation, ovulation induction was performed by daily injections of 150-300 IU of Highly Purified human FSH (Fostimon, IBSA) or 150-300 IU of follitropin alfa (Gonal F, Serono)

The ovulation was triggered by $10,000 \mathrm{IU}$ of hCG (Choriomon 5000 IU Amp, IBSA; or Pregnyl, 5,000 IU amp, Organon llac San.), when there were at least two leading follicles with a diameter of $>18 \mathrm{~mm}$. After 34-36 hours, egg collection was performed by transvaginal ultrasound. In vitro fertilization or intracytoplasmic sperm injection and embryo transfer was performed for all the patients. Luteal phase support was performed by progesterone (Utrogestan, $100 \mathrm{mg}$ cap., two vaginal capsules three times per day; BesinsI'scovesco Lab., Paris, France or $8 \%$ Crinone gel one dose per day).

To identify patients with potentially difficult ET in order to measure the uterine cavity depth and direction of the cervix and the uterus, on the day of first ultrasound axme for the control of ovarian stimulation, the distance between the fundus of the uterine cavity (end of the endometrial image) and the internal ostium of the cervical canal was measured by transvaginal ultrasound.

Two to three days after oocyte recovery, usually two, but occasionally three embryos per patient were replaced depending upon the age of the patient, the indication for IVF, the number of previous IVF attempts, and the number and quality of embryos available for replacement.

The highest quality embryos were selected for transfer, with quality being assessed based on cell number and number of cytoplasmic fragments. Embryos were classified as follows: grade 1: perfectly symmetrical with no fragmentation; grade 2: perfectly symmetrical with slight fragmentation $(<20 \%$ fragmentation of the total embryonic volume); grade 3 : uneven blastomeres with gross fragmentation ( $>20 \%$ fragments) [29, 30]. Embryos of Veeck grades 1 or 2 were considered high quality. All transfers were performed in the same IVF operating room suite with the patient in the lithotomic position, with a comfortably full bladder and the cervix was exposed using a bivalve speculum. The exocervix was cleaned and endocervical mucus was removed with a sterile catheter connected to a syringe containing culture medium. 
The catheter (Soft-trans embryo transfer catheter set, Sydney COOK, Australia) was first filled with transfer medium (Sydney COOK, Australia). Next, the transfer medium containing the embryos was loaded into the catheter between air bubbles, and finally more transfer medium was added (maximum total volume: $30 \mu \mathrm{l}$ )

Prior to embryo transfer, the endometrial thickness, the distance from the external cervical os to the fundal endometrial surface, and the point that the tip of the catheter should reach for embryo replacement were measured by means of transabdominal and transvesical (with full bladder) ultrasonograhy with an Toshiba, Diagnostic ultrasound system, Nemio SSA-550 A; Shimoishiogami; japan) with real time transabdominal convex transducer 3.75 $\mathrm{MHz}$. In order to facilitate this measurement, the speculum was withdrawn, if necessary, so that the external cervical os could be seen.

Under direct transabdominal ultrasound guidance, the transfer catheter was then advanced through the endocervical canal into the lower uterine segment. Immediate identification of the catheter tip was essential to minimize motion of the catheter and avoid any impact on the endometrium. The transfer catheter then was advanced to a defined distance from the uterine fundus, up to the point estimated for transfer: $10 \pm 2.5 \mathrm{~mm}$ and $15 \pm 2.5 \mathrm{~mm}$ respectively in $A$ and $B$ group. This measurement was verified by using the calipers prior to injection of the embryos. The distance between the end of the fundal endometrial surface and the catheter tip was then again measured by ultrasound and considered for analysis of the results. In all transfers, the medium containing the embryos was gently expelled into the uterine cavity under ultrasound monitoring, with the volume being sufficient to permit the ultrasonographic visualization of the transfer inside the uterine cavity, which was also facilitated by the presence of air bubbles ('transfer bubbles') between the embryos. After transfer, the catheter was held in place for 30 to 45 seconds to permit the embryos to settle away from the catheter tip. The transfer and guide catheters were then slowly withdrawn as a unit and inspected for any retained embryos and to detect bleeding. Transfer was performed by the same provider (M.I.) in al patients included in the present study. The same transfer technique was maintained with all patients.

Clinical pregnancy was defined as the presence of gestational sac by ultrasound with appropriately rising B-hCG levels. Miscarriage was defined as pregnancy loss before 12 weeks of gestation.

\section{Statistical analysis}

The collected data were input into a computer database, pre- defined according to a specially prepared form and software for the needs of the study. The data processing as well as their analysis was done with the statistical software "Statistica for Windows/Release 7.1".

We used the $x^{2}$-test to compare qualitative variables, and Student's $t$-test to compare quantitative variables. Data are reported as means ( \pm SD). The significance level was set at $P<0.05$.

\section{Results}

Of the patients studied, $88(55 \%)$ were less than 35 years old, with only $20(12.5 \%)$ more than age 40 years. In only $5.9 \%$ transfers was blood noted on the catheter tip; and $85.7 \%$ of transfers were rated as easy. The remaining transfers were moderately difficult. The patients were divided into two groups according to the distance between the tip of the catheter and the uterine fundus at the time of embryo deposition in the cavity: group A : $10 \pm 2.5 \mathrm{~mm}$; group $\mathrm{B}: 15 \pm 2.5 \mathrm{~mm}$ (Figure 1 and Figure 2).

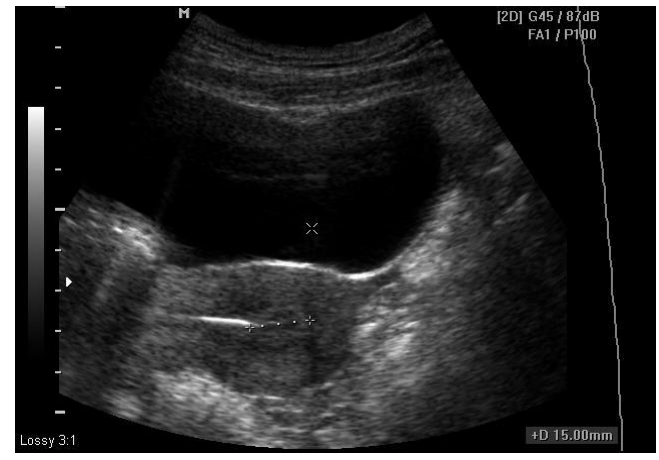

Figure 1: (Group B) Transfer distance from fundus $15 \pm 2.5 \mathrm{~mm}$

Both groups proved to be comparable regarding the main demographic characteristics, as well as the main cycles parameters (without statistically significant differences) (Table 1).

Table 1: Comparison between main demographic and baseline characteristics of patients in different depth of embryo transfer replacement (transfer distance from fundus > group A: $10 \pm 2.5$ $\mathrm{mm}$; group $B: 15 \pm 2.5 \mathrm{~mm}$ )

\begin{tabular}{lccc}
\hline $\begin{array}{l}\text { Main demographic and baseline } \\
\text { characteristics of patients }\end{array}$ & $\begin{array}{c}\text { Group A : 10 } \\
\mathrm{mm}(\mathrm{N}=84)\end{array}$ & $\begin{array}{c}\text { Group B 15 } \pm \\
2.5 \mathrm{~mm} \\
(\mathrm{~N}=76)\end{array}$ & $\begin{array}{c}\mathrm{T} \\
\text { test }\end{array}$ \\
\hline Age (year) \pm SD & $33.7 \pm 5.2$ & $34.9 \pm 6.8$ & $\mathrm{NS}$ \\
Duration of infertility (year) & $5.2 \pm 3.6$ & $6.3 \pm 5.4$ & $\mathrm{NS}$ \\
No of cycles performed & $2.4 \pm 1.7$ & $2.1 \pm 1.2$ & $\mathrm{NS}$ \\
Primary infertility & $65(77 \%)$ & $61(80.2 \%)$ & $\mathrm{NS}$ \\
Male factor & $34(40.47 \%)$ & $35(46 \%)$ & $\mathrm{NS}$ \\
Tubal factor & $20(23.8 \%)$ & $15(19.7 \%)$ & $\mathrm{NS}$ \\
Unexplained & $30(35.7 \%)$ & $26(34.2 \%)$ & $\mathrm{NS}$ \\
Baseline FSH level ( IU/L) & $6.9 \pm 3.9$ & $7.3 \pm 3.3$ & $\mathrm{NS}$ \\
Baseline LH level (mIU/L) & $5.8 \pm 4.84$ & $6.1 \pm 3.7$ & $\mathrm{NS}$ \\
Baseline Oestradiol level (pg/ml) & $29.5 \pm 11.73$ & $28.77 \pm 10.67$ & $\mathrm{NS}$ \\
\hline
\end{tabular}

The mean number of embryos transferred per cycle was 2.1. A mean E2 levels on HCG day was $2044 \mathrm{pg} / \mathrm{ml}$. Overall clinical pregnancy were 41.2\%. There were not significantly differences between the two groups in term of embryo transfer characteristics 
(full bladder, ease of transfer, use of tenaculum, bleeding etc.) (Table 2).

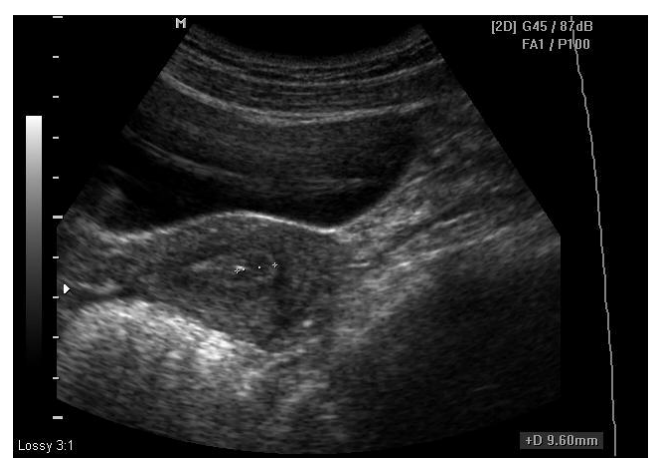

Figure 2: (Group A) Transfer distance from fundus $10 \pm 2.5 \mathrm{~mm}$.

Our results show that there was not significantly differences between two groups in term of gonadotropin ampoules administered (34.3 \pm 14.7 in group A vs. $32.2 \pm 12.8$ in group $B$ ); Estradiol levels on the day of HCG day (2107 \pm 985 in group $A$ vs $1980 \pm 1105$ in group $B$ ), mean of oocytes retrieval and embryo transferred (ET) $(9.2 \pm 6.2$ vs $8.9 \pm 5.8$; $2.2 \pm 08$ vs $1.9 \pm 1.2$ respectively in group $A$ and $B$ ), and grade of transferred embryos. Analysis of our results demonstrated that pregnancy rate is significantly influenced by transfer distance from the fundus where the pregnancy rate decreases from $48.7 \%$ in group $B$ to $34.5 \%$ in group $A(p<0.05)$. There was not significantly difference in abortion rate between the two groups.

Table 2: Comparison between patient's ovarian stimulation characteristics, oocyte retrieval; embryo transfer characteristics and pregnancy/miscarriage rates in different depth of embryo transfer replacement (transfer distance from fundus > group A: $10 \pm 2.5 \mathrm{~mm}$; group $B: 15 \pm 2.5 \mathrm{~mm}$ ).

\begin{tabular}{lccc}
\hline Ovarian stimulation characteristics & $\begin{array}{c}\text { Group A: } \\
10 \pm 2.5 \\
\mathrm{~mm}(\mathrm{~N}=84)\end{array}$ & $\begin{array}{c}\text { Group B 15 } \\
2.5 \mathrm{~mm} \\
\text { and oocyte retrieval }\end{array}$ & T test \\
& & & \\
\hline Estrogen level on HCG day $(\mathrm{pg} / \mathrm{ml})$ & $2107 \pm 985$ & $1980 \pm 1105$ & $\mathrm{NS}$ \\
No of Gonadotropin ampules & $34.3 \pm 14.7$ & $32.2 \pm 12.8$ & $\mathrm{NS}$ \\
No of retrieved oocytes & $9.2 \pm 6.2$ & $8.9 \pm 5.8$ & $\mathrm{NS}$ \\
Embryo transfer characteristics and pregnancy/miscarriage rates & \\
No of transferred embryos & $2.2 \pm 0.8$ & $1.9 \pm 1.2$ & $\mathrm{NS}$ \\
Endometrial thickness on ET day & $11.7 \pm 3.6$ & $10.4 \pm 2.9$ & \\
Easy of transfer \% & $72(85.7 \%)$ & $66(86.8 \%)$ & \\
Use of tenaculum & $5(5.9 \%)$ & $3(3.9 \%)$ & \\
Bleeding & $5(5.9 \%)$ & $4(5.2 \%)$ & \\
Repeated transfer & $2(2.38 \%)$ & $1(1.31 \%)$ & \\
Pregnancy rate & $29(34.5 \%)$ & $37(48.7 \%)$ & $\mathrm{p}<0.05$ \\
\hline
\end{tabular}

\section{Discussion}

The goal of embryo transfer is to successfully deliver the embryos atraumatically to the desired location in the uterine cavity to maximize implantation. It seems reasonable that visualization of the drop-off site, such as with US, to ensure favorable embryo transfer position would be desirable.
The 'clinical touch' method was first described by Steptoe and Edwards and is a well-known technique for embryo transfer [31]. This technique consists of the insertion of a catheter into the cavity until touching the fundal endometrium, followed by a $5-10 \mathrm{~mm}$ retreat and subsequent deposition of the embryos.

Waterstone et al., 1991 suggested that the site of deposition of the embryos within the uterine cavity could have profound effects on success rates [28]. Later this finding was also substantiated by Naaktgeboren, 1998 [32]. By applying a technique in which the embryos are expelled at a fixed distance from the external os, a remarkable decrease was observed in the variability in success rates among physicians: most physicians approximated the success rates of the best-performing physician [24, 32]. When using the fixed distance technique, embryos are being transferred at $6 \mathrm{~cm}$ from the external os irrespective of the individual length of the uterus. This means that assessing the sounding length of the uterus before applying the fixed distance method and using a distance $\sim 1.5-2 \mathrm{~cm}$ away from the fundus may optimize the performance of the fixed distance transfer procedure.

Ultrasound-guided embryo transfer (UGET) during an IVF cycle was initially reported during the mid-1980s [11, 33] and has gradually become an integral part of the embryo transfer technique for many IVF clinics. Some studies have demonstrated a benefit in favour of UGET when compared to embryo transfer without ultrasound guidance [19, 34-38] although others have not $[14,15,39]$. Careful examination of the data from four properly randomized clinical trials [19, 34, 36, 39] showed a significant advantage to UGET with regard to implantation, clinical pregnancy, and ongoing pregnancy rates [7, 38].

Among the various aspects of embryo transfer, the site of embryo placement in the uterine cavity has been postulated to influence embryo implantation rates. Whereas some investigators believe that higher levels in the endometrial cavity closer to the uterine fundus lead to higher rates [40, 41], others have suggested that improved embryo transfer results are obtained when the embryos are placed at lower levels in the uterine cavity [12, 24, 28, 32, 34, 42-45]. Waterstone et al., 1991 reported the results of embryo transfer performed by two clinicians who followed different techniques [28]. The former one introduced the catheter until he felt the fundus and then pulled it back $5 \mathrm{~mm}$ before injecting the embryos, and achieved a final pregnancy rate of $24 \%$. The other clinician introduced the catheter until a depth of $5 \mathrm{~cm}$ from the external orifice of the cervix and deposited the embryos without touching the fundus, and obtained a pregnancy rate of $46 \%$. When the first clinician modified his technique according to that of the second, improvement in pregnancy rates was observed. Coroleu et al., 2002 demonstrated in a 
prospective randomized trial of women undergoing UGET that the pregnancy rate was significantly higher when the embryos were transferred at $1.5-2.0 \mathrm{~cm}$ instead of at $1.0 \mathrm{~cm}$ from the uterine fundus [34]. Frankfurter et al., 2003 retrospectively analyzed 23 patients who underwent two cycles of ultrasoundguided embryo transfer each, considering for each patient a transfer that resulted in pregnancy and one that did not [42]. The results showed better pregnancy rates when the site of embryo placement relative to the length of the endometrial cavity was more distant from the uterine fundus. No significant difference was observed when comparing the absolute distance.

In our study there were no differences in age, number of days of ovarian stimulation, total number of oocyte retrieved, and number of good quality embryos between these groups of patients. There was statistically significant difference in pregnancy rate (group $A=34.5 \%$ vs group $B=48.7 \%$ ) respectively, with $\mathrm{P}<0.05$.

One study retrospectively demonstrated that for every additional millimeter embryos were deposited away from the fundus, as noted by abdominal ultrasound, the odds of clinical pregnancy increased by $11 \%$ [46]. However, not all studies show an association between embryo transfer location and outcome [27]. In addition, others demonstrate that the best site for embryo transfer is the centre of the uterine cavity, and that the relative site of embryo deposition is more important than the actual distance from the fundus [47, 48]. Finally, some authors postulate that the question regarding the site of embryo transfer is of no importance since it does not influence implantation as long as embryos are placed in the upper half of the cavity [25, 27].

Two dimensional sonography has still only provided guidance as to the general area at which the embryo should be released for implantation. 3D sonography can improve visualization of the uterus in patients with normal anatomy and especially in those with congenital uterine anomalies. Thus, the present invention provides a maximal implantation potential (MIP) point as a target for embryo transfers. Embryo transfers at the MIP were associated with good implantation and pregnancy rates [49].

It is not fully understood why the pregnancy rate is higher with the transfer of embryos lower in the uterine cavity. One theory suggests that catheter contact with the uterine fundus may be avoided when embryos are transferred to the lower part of the uterine cavity. Strong fundo-uterine contractions can result from fundal contact $[3,50]$, which may have a negative impact on pregnancy rates [43, 44]. It is inevitable that insertion of the catheter- after all a foreign body- may interfere with normal uterine peristalsis. Embryos often relocate from the uterine cavity after IVF/ET. They have been found in the vagina $[51,52]$ and there is a high ectopic pregnancy rate, ranging from $2.1 \%$ [53] to $9.4 \%$ [54] after assisted conception treatment. It is worth remembering that the very first pregnancy conceived after IVF/ET was an ectopic gestation in the fallopian tube [31]. The evidence that this relocation is the consequence of junctional zone contractions is considerable. Experimental studies of mock ET in humans have demonstrated the expulsion of methylene blue in 57\% of transfers [55] and the movement of X-ray contrast medium towards the fallopian tubes and cervix/vagina in $38 \%$ and $21 \%$, respectively [56]. In observations of junctional zone contractions after easy and difficult mock ETs, Lesny et al., 1998 use of different catheters [3], application of a tenaculum to the cervix [43] or stimulation of contractions after transmyometrial ET [44, 57], all report increased contractions following increasing trauma at the time of ET. Using mock ET in oocyte donor patients as a model, it was shown that even minimal stimulation such as touching the uterine fundus with the soft end of the ET catheter is capable of generating evident contractions, which can relocate mock embryos (a bolus of the echogenic substance Echovist) from the upper part of the uterine cavity towards the cervix or into the fallopian tubes.

In addition to traumatic manipulation of the cervix and touching the fundus, the mere presence of the transfer catheter might be one of the factors that can trigger uterine contractions $[43,44]$.

In summary, compared with the traditional method, abdominal ultrasound-guided embryo transfer has a number of potential benefits. First, with the guidance of ultrasound, the catheter can be bent to easily pass through the cervical canal and follow the uterine axis, which helps avoid overstimulation and reduction in incidence of difficult transfers, endometrial trauma, and bleeding that can cause excessive fundo-uterine contractions at the time of embryo transfer has been associated with lower clinical pregnancy rates $[2,10]$. Second, the entire process of catheterization and release of the embryos can be visualized, making it easier to place the embryos in the correct position within the uterus and decrease the chance of improper embryo placement. In addition, the full bladder required for transabdominal ultrasound itself is useful for the correction of uterine access through the cervical route in cases of pronounced anteversion-anteflexion. In particular, the main disadvantages of using ultrasound guidance during embryo transfer may be the additional time and personnel required, as well as patient discomfort due to a full bladder and the urge to urinate [7].

Our data seems to show a significant increase in pregnancy rate and implantation rate in B group, where there was a distance $15 \pm 2.5 \mathrm{~mm}$ between the tip of the catheter and uterine fundus. What we want to show in our study is that, although baseline patient clinical characteristics, treatment cycles characteristics, ovarian response and any variable of embryo 
transfer (type of catheter, difficulty of transfer, bleeding, use of tenaculum) were all similar in the two groups studied, we found a statistically significant difference in PR and IR between the two groups. We avoided any impact of the physician factor on implantation rate because all transfer was carried out by the same provider. In addition we didn't find a statistically significant difference in abortion rate between the two groups studied.

In conclusion, our results suggest that depth of embryo replacement inside the uterine cavity may influence the pregnancy rates and should be considered as an important factor to improve the success of IVF cycles.

Using ultrasound controlled embryo transfer; various studies have suggested that replacement further away from the fundus will improve implantation rates. As no clear answer exists to the question in what part of the cavity (maximal implantation potential point) the embryos need to be expelled from the catheter to obtain the best pregnancy rates, further study is needed at this point. Because of individual anatomic differences the maximal implantation potential point should be readily identified and individualized for each patient. Though still larger studies are needed to established more precise maximal implantation potential point and achieve better pregnancy rates with ART procedures.

\section{References}

1. Edwards, R.G. Clinical approaches to increasing uterine receptivity during human implantation. Hum. Reprod., 1995 10 (Suppl. 2): 60-66.

2. Goudas, V.T., Hammitt, D.G., Damario, M.A., Session, D.R. Singh, A.P. and Dumesic, D.A. Blood on the embryo transfer catheter is associated with decreased rates of embryo implantation and clinical pregnancy with the use of in vitro fertilization-embryo transfer. Fertil. Steril.1998; 70, 878-882.

3. Lesny $P$, Killick SR, Tetlow RL, Robinson $\mathrm{J}$ and Maguiness $\mathrm{SD}$. Embryo transfer-can we learn anything new from the observation of junctional zone contractions? Hum Reprod. 1998; 13: 1540-1546.

4. Lesny P, Killick SR, Robinson J, Raven G, Maguiness SD. Embryo transfer and junctional zone contractions: is it safe to use a tenaculum? Hum Reprod. 1999; 14:2367- 2370.

5. Schoolcraft WB, Surrey ES and Gardner DK. Embryo transfer: techniques and variables affecting success. Fertil Steril. 2001; 76: 863-870.

6. Mansour RT and Aboulghar MA. Optimizing the embryo transfer technique. Hum Reprod. 2002; 17: 1149-1153.

7. Buckett WM. A meta-analysis of ultrasound-guided versus clinical touch embryo transfer. Fertil Steril. 2003; 80:10371041.

8. Levi Setti PE, Albani E, Cavagna M, Bulletti C, Colombo GV and Negri L. The impact of embryo transfer on implantation-a review. Placenta 24 (Suppl B). 2003: 20-26.

9. Mirkin S, Jones EL, Mayer JF, Stadtmauer L, Gibbons WE and Oehninger S. Impact of transabdominal ultrasound guidance on performance and outcome of transcervical uterine embryo transfer. J Assist Reprod Genet. 2003; 20: 318-322.

10. Sallam HN and Sadek SS. Ultrasound-guided embryo transfer: a metaanalysis of randomized controlled trials. Fertil Steril. 2003; 80: 1042-1046.

11. Strickler RC, Christianson C, Crane JP, Curato A, Knight AB and Yang V. Ultrasound guidance for human embryo transfer. Fertil Steril. 1985; 43: 54-61.
12. Woolcott R, Stanger J. Potentially important variables identified by transvaginal ultrasound-guided embryo transfer. Hum Reprod. 1997; 12: 963-6.

13. Hurley VA, Osborn JC, Leoni MA, Leeton J. Ultrasound guided embryo transfer: a controlled trial. Fertil Steril. 1991; 55:559_ 62.

14. Al-Shawaf T, Dave R, Harper J. Transfer of embryos into the uterus, how much do technical factors affect pregnancy rates? J Assiss Reprod Genet; 1993; 10:31-6.

15. Kan AK, Abdalla HI, Gafar AH. Embryo transfer: ultrasound guided versus clinical touch. Hum Reprod. 1999; 14:1259-61.

16. Prapas Y, Prapas N, Hatziparasidou A. The echoguide embryo transfer maximizes the IVF results. Acta Eur Fertil. 1995; 26:113-5.

17. Coroleu B, Carreras O, Veiga A, Martell A, Martinez F, Belil I, Hereter L and Barri PN. Embryo transfer under ultrasound guidance improves pregnancy rates after in-vitro fertilization. Hum Reprod. 2000; 15: 616-620.

18. Wood EG, Batzer F, Go KJ, Gutmann J, Corson SL. Ultrasound guided soft catheter embryo transfer will improve pregnancy rates in in-vitro fertilization. Hum Reprod.2000; 15:107-12.

19. Tang OS, $\mathrm{Ng} \mathrm{EH}$, So WW. Ultrasound-guided embryo transfer: a prospective randomized controlled trial. Hum Reprod. 2001;11:2310-5.

20. Kovasc GT. What factors are important for successful embryo transfer after in-vitro fertilization? Human Reprod. 1999;14: 590- 92

21. Salha $\mathrm{OH}$, Lamb VK, Balen $\mathrm{AH}$. Apostal survey of embryo transfer practice in UK. Hum Reprod. 2001;16:686-90.

22. Leeton J, Trounson A, Jessup D,Wood C. The technique of human embryo transfer. Fertil Steril. 1982; 38:156-61.

23. Kojima K, Nomiyama M, Kumamoto T, Matsumoto Y, Iwasaka $T$. Transvaginal ultrasound-guided embryo transfer improves pregnancy and implantation rates after IVF. Hum Reprod. 2001;16: 2578-82.

24. Naaktgeboren N, Broers FC, Heijnsbroek I. Hard to believe, hardly discussed, nevertheless very important for the IVF/ICSI results: embryo transfer technique can double or halve the pregnancy rate. Hum Reprod. 1997; 12:149.

25. Nazari A, Askari HA, Check JH and O, Shaughnessy A. Embryo transfer technique as a cause of ectopic pregnancy in in-vitro fertilization. Fertil Steril. 1993; 60: 919-921.

26. Pacchiarotti A, Mohamed AM, Micara G, Tranquilli D, Linari A, Aspinola S, Cesare A. The impact of the depth of embryo replacement on IVF outcome. J Assist Reprod Genet. 2007; 24: 189-193

27. Roselund B, Sjoblom P, Hillensjo T. Pregnancy outcome related to the site of embryo deposition in the uterus. J Assist Reprod Genet. 1996; 12:511-3.

28. Waterstone J, Curson R, Parsons J. Embryo transfer to low uterine cavity.Lancet. 1991;337:1413.

29. Veeck L. The morphological assessment of human oocytes and early concepti. In: Keel BA, Webster BW, eds. Handbook of the laboratory diagnosis and treatment of infertility. Boca Raton, FL: CRC Press, 1990:353-69.

30. Veeck L. The morphological assessment of human oocytes and early concepti. In: Keel BA, Webster BW, eds. Handbook of the laboratory diagnosis and treatment of infertility. Boca Raton, FL: CRC Press, 1990:353-69.

31. Steptoe, P.C. and Edwards, R. Reimplantation of a human embryo with subsequent tubal pregnancy. Lancet. 1976; 1: $880-882$.

32. Naaktgeboren, N., Dieben, S., Heijnsbroek, I., Verburg, H. and Van der Westerlaken, L. Embryo transfer, easier said than done. Abstracts of the 16th World Congress on Fertility and Sterility and 54th Annual Meeting of the American Society for Reproductive Medicine, San Francisco, CA, USA, S352. 1998

33. Leong $M$, Leung $C$, Tucker $M$, Wong $C$ and Chan $H$. Ultrasound-assisted embryo transfer. $\mathrm{J}$ in Vitro Fertil Embryo Transfer. 1986; 3: 383-385.

34. Coroleu B, Barri PN, Carreras O, Martinez F, Parriego M, Hereter L, Parera N, Veiga A and Balasch J. The influence of the depth of embryo replacement into the uterine cavity on implantation rates after IVF: a controlled, ultrasound-guided study. Hum Reprod. 2002; 17:341-346. 
35. Ivanovski M. Comparison of ultrasound guided embryo transfer and previous failed blind embryo transfer in IVF cycles. XVIII FIGO World Congress of Gynecology and Obstetrics; Kuala Lumpur, Malaysia; Book of abstracts. 2006: 160.

36. Matorras R, Urquijo E, Mendoza R, Corcostegui B, Exposito A and Rodriguez-Escudero FJ. Ultrasound-guided embryo transfer improves pregnancy rates and increases the frequency of easy transfers. Hum Reprod. 2002; 17:17621766.

37. Prapas $Y$, Prapas N, Hatziparasidou A, Vanderzwalmen P, Nijs $M$, Prapa $S$ and Vlassis G. Ultrasound-guided embryo transfer maximizes the IVF results on day 3 and day 4 embryo transfer but has no impact on day 5 . Hum Reprod. 2001; 16 : 1904-1908.

38. Sallam HN, Agameya AF, Rahman AF, Ezzeldin F and Sallam AN. Ultrasound measurement of the uterocervical angle before embryo transfer: a prospective controlled study. Hum Reprod. 2002; 17: 1767-1772.

39. Garcia-Velasco JA, Isaza V, Martinez-Salazar J, Landazabal $\mathrm{A}$, Requena A, Remohi $\mathrm{J}$ and Simon C. Transabdominal ultrasound-guided embryo transfer does not increase pregnancy rates in oocyte recipients. Fertil Steril. 2002; 78,534-539.

40. Krampl E, Zegermacher G, Eichler C, Obruca A, Strohmer H and Feichtinger $W$. Air in the uterine cavity after embryo transfer. Fertil Steril. 1995; 63: 366-370.

41. Meldrum DR, Chetkowski R, Steingold KA, de Ziegler D, Cedars $\mathrm{Ml}$ and Hamilton M. Evolution of a highly successful in vitro fertilization embryo transfer program.Fertil Steril. 1987; 64: 382-389.

42. Frankfurter D, Silva CP, Mota F, Trimarchi JB and Keefe D. The transfer point is a novel measure of embryo placement. Fertil Steril . 2003; 79, 1416-1421

43. Lesny P, Killick SR, Robinson J, Titterington J, Maguiness SD Case report: ectopic pregnancy after transmyometrial embryo transfer. Fertil Steril. 1999; 72:357 -359.

44. Lesny P, Killick SR, Tetlow RL, Robinson $\mathrm{J}$ and Maguiness SD. Embryo transfer and uterine junctional zone contractions. Hum Reprod Update. 1999; 5: 87-88.

45. Van de Pas MMC, Weima S, Looman CWN and Broekmans FJM. The use of fixed distance embryo transfer after IVF/ICSI equalizes the success rates among physicians. Hum Reprod. 2003; 18: 774-780.

46. Pope CS, Cook EKD, Arny M, Novak A and Grow DR (2004) Influence of embryo transfer depth on in vitro fertilization and embryo transfer outcomes. Fertil Steril. 2004; 81: 51-58.

47. Franco JG Jr, Martins AM, Baruffi RL, Mauri AL, Petersen CG, Felipe V, Contart P,Pontes A, Oliveira JB. Best site for embryo transfer: the upper or lower half of endometrial cavity? Hum Reprod. 2004;19:1785-1790.

48. Oliveira JB, Martins AM, Baruffi RL, Mauri AL, Petersen CG, Felipe V, Contart P, Pontes A and Franco Junior JG. Increased implantation and pregnancy rates obtained by placing the tip of the transfer catheter in the central area of the endometrial cavity. Reprod Biomed Online. 2004; 9: 435-441.

49. Gergely RZ, DeUgarte CM, Danzer H, Surrey M, Hill D, DeCherney $\mathrm{AH}$. Three dimensional/four dimensional ultrasoundguided embryo transfer using the maximal implantation potential point. Fertility and Sterility. 2005;84: 500-503.

50. Fanchin, R., Righini, C., Olivennes, F., Taylor, S., Ziegler de, D. and Frydman, R. Uterine contractions at the time of embryo transfer alter pregnancy rates after in-vitro fertilization. Hum Reprod. 1998; 13: 1986-1974.

51. Poindexter AN, Thompson DJ, Gibbons WE, Findley WE, Dodson MG, Young RL. Residual embryos in failed embryo transfer. Fertil Steril. 1986; 46: 262- 267.

52. Schulman JD. Delayed expulsion of transfer fluid after IVF/ET. Lancet. 1986; 1:44.

53. Azem $\mathrm{F}$, Yaron $\mathrm{Y}$, Botchan A. Ectopic pregnancy after in vitro fertilization -embryo transfer (IVF/ET): the possible role of the ET technique. J Assist Reprod Genet. 1993; 10:302- 304.

54. Zouves C, Erenus M, Gomel V. Tubal ectopic pregnancy after in vitro fertilization and embryo transfer: a role for proximal occlusion or salpingectomy after failed distal tubal surgery. Fertil Steril. 1991; 56: 691-695.
55. Mansour RT, Aboulghar MA, Serour GI, Amin YM. Dummy embryo transfer using methylene blue. Hum Reprod. 1994; 9: 1257-1259.

56. Knutzen V, Stratton CJ, Sher G, McNamee PI, Huang TT, Soto- Albors C . Mock embryo transfer in early luteal phase, the cycle before in vitro fertilization and embryo transfer a descriptive study. Fertil Steril. 1992; 57:156- 162.

57. Biervliet FP, Lesny P, Maguiness SD, Robinson J, Killick SR. Transmyometrial embryo transfer and junctional zone contractions. Hum Reprod; 2002; 17:347-350. 